Microlearning: Knowledge management applications and competency-based training in the workplace

Lynn C. Emerson

Judicial College of Maryland, Annapolis, MD, USA

Zane L. Berge

University of Maryland, Baltimore County, MD, USA

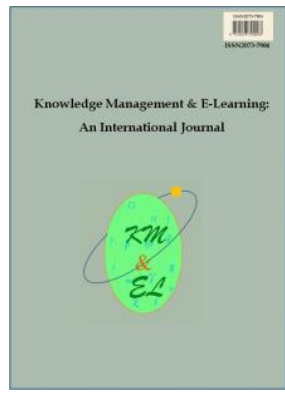

Knowledge Management \& E-Learning: An International Journal (KM\&EL) ISSN 2073-7904

Recommended citation:

Emerson, L. C., \& Berge, Z. L. (2018). Microlearning: Knowledge management applications and competency-based training in the workplace. Knowledge Management \& E-Learning, 10(2), 125-132. 


\title{
Microlearning: Knowledge management applications and competency-based training in the workplace
}

\author{
Lynn C. Emerson \\ Judicial College of Maryland, Annapolis, MD, USA \\ E-mail: Lynn.Emerson@mdcourts.gov
}

\author{
Zane L. Berge* \\ Department of Education \\ University of Maryland, Baltimore County, MD, USA \\ E-mail: berge@umbc.edu
}

*Corresponding author

\begin{abstract}
The focus of this article is a threefold discussion on microlearning 1) how microlearning best practices facilitate knowledge acquisition in the workplace by engaging and motivating employees through short, personalized, just-in-time learning, 2) ways microlearning integrates with knowledge management applications through situational mentoring, and 3) how competency-based microlearning, via subscription learning, is both an innovative approach to e-learning and an asset to learning organizations focused on improving the performance of their employees.
\end{abstract}

Keywords: Microlearning; Knowledge management applications; Competency-based training; Workplace

Biographical notes: Lynn Emerson is the Learning and Performance Specialist at the Judicial College of Maryland. She is guiding the Maryland State Judiciary's efforts in developing online and hybrid competency-based training programs that will reach more than 65 percent of Maryland's judiciary workforce. She is facilitating the integration of adult learning principles, microlearning, gamification, and knowledge management strategies into performance-based e-learning training programs, making the Maryland State Judiciary the National leader in providing state-level competency-based judicial education. Lynn is also earning her master's in Instructional Systems Development at University of Maryland, Baltimore County with emphasis in instructional technology, distance education, adult learning, and human performance technology.

Dr. Zane Berge is Professor in the Training Systems graduate programs at the University of Maryland, Baltimore County campus. He teaches graduate courses involving training in the workplace and distance education. Prior to UMBC, Dr. Berge was founder and director of the Center for Teaching and Technology, Georgetown University, Washington DC. There is where he first combined his background in business with educational technology working in the areas of online scholarly journals and discussion lists, and online education and training. Today he specializes in distance education and online learning. 


\section{Introduction}

The paradigm shift in communication and consumption of information from printed tomes to digital texts no longer makes the headlines. Reading the daily news in bite-sized snippets, searching a wiki to learn how to properly check the air pressure in your car's tires, or watching a YouTube video on the best way to bake a cake is not just the norm for Millennials but are also established practices for Generation X and Baby Boomers. With Web 2.0 and social media driving the way, microlearning-learning in short, focused bursts designed to meet specific knowledge outcomes-is all around us. This is especially true in our personal lives, and most people are usually connected at work as well.

As many organizations shift their focus from in-person workshops to incorporating more e-learning opportunities for their employees, they may be best served by fueling their professional development programs with a combination of microlearning strategies and knowledge management practices. The focus of this article is threefold. First, we will discuss microlearning best practices to facilitate knowledge acquisition in the workplace by engaging and motivating employees through short, personalized, justin-time learning. Second, we will identify how microlearning integrates nicely into knowledge management practices through situational mentoring. Third, we will analyze how competency-based microlearning, via subscription learning, is both an innovative approach to e-learning and an asset to learning organizations focused on improving the performance of their employees.

\section{Microlearning in the workplace}

Forward thinking, innovative companies such as the Cathay Life Insurance Co. LTD (Salopek, 2016) and the Maryland State Board of Public Accountancy (McCabe, 2016) have maneuvered their training efforts in a Porsche-like manner, to take full advantage of flexible microlearning strategies while engaging and educating their employees using mobile devices. Still, the organizational learning practices of many companies drive more like the family minivan and have only recently pulled out of the workshop parking lot. Those companies are still looking over their shoulders as they slowly merge onto the elearning highway.

In-person training is no longer premier in the workplace. Benchmarking results indicate that managers prefer on-demand learning and access to up-to-date information in a timely manner (Overton, 2011). As technology continues to be integrated into employees' daily tasks, more blended approaches to training and development are being used to move learning into the workplace. By delivering discrete chunks of information in short bursts of time, often via social media, microlearning is a strategy that complements more comprehensive classroom and web-based training by reinforcing concepts between tasks in the office or working as job aids on the production floor.

By incorporating multimedia into focused, interactive learning events that are, according to Pandey (2016) and Fox (2016) no more than three to five minutes long, microlearning interactions are simple enough to benefit first-time users (Willers, 2016) and function as extensions of the norm for veterans of social media. Employees can expand their knowledge incrementally for effective knowledge retention. Training departments can use knowledge management strategies to tag, index, and store microlearning modules in learning management systems for on-demand user access, updating, and referencing. 
Millennials are challenging traditional e-learning compliance-based methods, driving performance management strategies to evolve (Fox, 2016). According to Willers (2016), compliance training through microlearning can convey information directly and efficiently. Swift, Facebook-esque, knowledge questions involve learners in the content and also with the company overall (Shatto \& Ruiz, 2018; Tipton, 2017). This rapid feedback stimulates employees to become part of the organization's culture by increasing their sense of responsibility to observe compliance directives. Through microlearning, companies looking to develop as learning organizations can elevate compliance training to the new role of communicating and sharing a common vision to employees, inspiring them to work towards mission-critical organizational outcomes.

Compliance training by itself cannot make a learning organization. Still, the use of microlearning can be extended to customize learning plans between managers and employees (Fox, 2016). Fox explains that microlearning sets up a positive feedback loop that can accelerate staff development and increase employee retention by personalizing learning to build specific skill sets. The focused nature of microlearning allows specificity in content development over generic training programs that may easily miss the target. Rich, precise, and geared towards a specific audience, engaged and empowered learners retain more information because they decided, with guidance from their supervisors, what they needed to learn to perform their jobs better.

After all, business is about productivity and not necessarily about learning. From a performance management perspective, inserting learning interventions into a busy employee's schedule is a real challenge. Microlearning can achieve both, almost simultaneously, by supplying clear and concise well-designed single learning topics for staff to fit in-between tasks when they can spare 15 minutes.

Poulin (2013) cites instances where microlearning has a lasting, positive impact on the learning culture of an organization because it can be developed both from the topdown, in the traditional fashion, but also from the bottom-up. Smartphone video technology gives just about any employee the ability to capture in-depth institutional knowledge and share that information formally or informally throughout the organization.

Paul (2016) defines the anatomy of a microlearning module as having a title, a body, and an evaluation question. The title of a microlearning event is critical for accurate indexing purposes and to convey its use to the learner in a simple and direct manner. Learners use the title to decide whether to click to begin. The body focuses on giving the user an idea to think about and an action to carry out, with graphics and video delivering the greatest impact (Paul, 2016). Phrasing information in the form of a question is also an effective way to engage active learning. Think about all the "quizzes" so popular on Facebook these days. The use of interleaving, or mixing up information in unexpected ways, can also aid retention. Although Paul suggests that an evaluation of the module can come in the form of just one or two questions such as, "Did this resource give you the information you needed?" or "Would you recommend this resource?" a more personalized approach might be a better option in the workplace. The evaluations should include some sort of knowledge check, self-assessment, or application. For example, simple quiz questions help reinforce retention when teaching basic facts and selfassessments allow the learner to reflect and more actively process the information. By assigning tasks that require social interaction, learners can also share and apply new knowledge.

Microlearning may not be the best tool when the student is learning something for the first time or when learning a complex skill (Fox, 2016). Best used for reinforcement, microlearning can help the user polish or develop automaticity for a particular skill set. 
Microlearning could also be used as follow-up training after larger programs or for more specialized, supplemental training, when it is difficult to get people back into the classroom. This may be accomplished by building a searchable microlearning library of assets that can be viewed on a smartphone or a tablet which can be easily accessed by the end user and straightforward to update by the developer.

\section{Microlearning and knowledge management}

Microlearning has been touted as a strategy that can help deliver the right information to the right learners, at the right level of detail and at the precise moment they need it. This sentiment has also been attached to knowledge management methodologies (Rosenberg, 2014). Applying knowledge management principles to microlearning strategies may extend the reach of microlearning. Davenport (1994) describes knowledge management as the process of using informational technology to capture, distribute, and effectively use organizational knowledge. According to Rosenberg (2014) there are three major components of knowledge management: information repositories, communities of practice, and access to experts and expertise.

First, storing microlearning interventions in an indexed and searchable information repository, such as a learning management system or Intranet, is an obvious connection to knowledge management. After all, if employees cannot efficiently and effectively locate the required bits and bytes of information that microlearning can offer, then microlearning falls short as a successful learning strategy, regardless of content accuracy and pedagogical coherence.

Second, professional development in the workplace can be supported by using Web 2.0 and social software to inject microlearning into employee-based communities of practice. For example, pushing microlearning modules to an online community of supervisors allows learning organizations not only to steer informal learning and stimulate discussion, but it also encourages problem-solving of mission-critical issues and links goal-oriented solutions to the office.

Third, if microlearning indexing tags include an expert's contact information, then access to expertise beyond that of the microlearning event can provide additional depth and dissemination of knowledge. Given the fact that the role of a learning specialist is becoming more focused on helping employees find information rather than designing, developing, and delivering training as mentioned by Julie Clow (as cited in Hartley, 2010), it is intriguing to consider the idea of situational mentoring as a method of extending the reach of microlearning. Randy Emelo (as cited in Hartley, 2010) describes situational mentoring as a process similar to that of traditional mentoring in that the learners engage experts for information, advice, and feedback. Unlike traditional mentoring, however, the learners seek collaborators who can give them specific advice on a single, targeted issues that requires a quick resolution. The learner identifies and clarifies a situation or dilemma where information or creative input is required from others. The mentee then searches a database of potential mentors that have volunteered their help in a short-term, focused way. The learner then contacts the expert collaborators, usually one to three, to explore solutions for an agreed upon project plan. They meet virtually, face-to-face, or both to accomplish the project's goals and solutions. The collaborating group then post the results of their discoveries, so others can learn from the experience. Building on the idea of tagging an expert's contact information to a microlearning module, the constructs of situational mentoring could increase the range of microlearning into the realm of tacit knowledge, that depth of comprehension gained 
through practice and experience, such as speaking a different language and playing a musical instrument or qualities like leadership, innovation, and emotional intelligence (ADEC Innovations, 2016; Giurgiu, 2017).

\section{Microlearning and competency-based education and training}

If microlearning strategies can be an efficient conduit between knowledge management and institutional experts in the transfer of amorphous tacit capabilities, then contrary to Fox's (2016) belief, they can also be used to deliver more complex learning. For example, the incremental and granular nature of competency-based training is the prototypical example of microlearning in action. For learning organizations focused on effective job performance, competencies aimed at developing awareness, knowledge, and skills on the path to mastering more complex job behaviors can be delivered to the employee as separate, but sequential microlearning lessons.

From a knowledge management perspective, the considerable cost required to develop and implement competency-based education can be reduced, by the successful training of employees, and by the relative ease at which the competencies can be kept current in a microlearning environment. Political and economic shifts can cause many competency models to fall out of alignment with fluctuating organizational objectives. Campion, Fink, Ruggeberg, Carr, Phillips, and Odman (2011) emphasize that as much attention should be given to maintaining competency-based programs as is afforded to their initial development. If each competency is associated with a single learning objective taught in a microlearning lesson, then groups of lessons that make up the tasks in a job behavior can be easily identified for revision.

Delivery of competency-based microlearning should involve strategic integration into the workplace and effective use of social learning. Following the lead of Allen, Dirksen, Quinn, and Thalheimer (2014) in their appeal for practitioners to raise the bar and achieve more effectual e-learning designs, competency-based microlearning looks like it is an effective way to move away from the familiar form of an e-learning course. To accomplish this, job behaviors must be first accurately defined, followed by a task analysis for each behavior. Once competencies have been identified for each job behavior, they can be individually reordered and grouped pedagogically as required. From that point, each competency can be converted to a measurable learning objective from which each microlearning lesson can be developed. Each competency can also be incorporated into a self-assessment tool (Hughes \& Rycus, 1989). Six months to a year after training, the employee can use the instrument to measure strengths and identify areas that need additional support or refresher training. This individual training profile provides a mechanism to close performance gaps. Together with performance evaluations, the individual training needs assessment can provide supervisors with comprehensive pictures of the developmental state of their staff. Moreover, the training needs assessment data from all staff, which can be complied to evaluate the success of the curriculum and pinpoint microlearning lessons that should be revised. This approach to competency-based education captures the potential of research aligned tactics and innovative approaches to e-learning.

One such approach is subscription learning. Thalheimer (2014) suggests that subscription learning is a versatile delivery mechanism that can both augment traditional learning and provide alternatives to traditional approaches. Subscription learning takes the form of intermittent streams of learning related interactions, or "threads," that are pushed to subscribers via social media such as email, text messages, and cellphone alerts. 
These threads are microlearning events intentionally timed to support learning utilizing the spacing effect of distributed learning (Gerbier \& Toppino, 2015). In addition, microlearning threads ask learners to make decisions in simulations, answer scenariobased questions, access jobs aids, complete assignments, and encourage social reflection. In the words of Thalheimer (2014), "The bottom line is that subscription learning doesn't need to be limited to learning content. It can introduce job aids, on-the-job activities, and conversations with key stakeholders" (para. 9). Competency-based subscription learning can set the stage for critical thinking, problem-solving, and communication skills that learners can apply in the workplace to improve their performance.

Compared to traditional 30 to 90-minute e-learning classes, or one-day workshops where learners do not have the option to revisit the content presented, subscription learning can engage learners in many smaller blocks of learning while integrating the use of research validated strategies that typical online courses do not provide (Thalheimer, 2014). For example, subscription learning can afford learners opportunities to: encounter content over a relatively long-spaced interval to maximize knowledge retention; practice real-world tasks in context over time; and increase the likelihood that the acquired knowledge nuggets will be discussed with co-workers.

This novel approach to competency-based learning can be taken one step farther, especially when teaching new or complex behaviors. After a series of competency-based microlearning lessons have been delivered, confirm employee comprehension and encourage application by having them discuss the topics with a mentor, participate in a webinar, join a video conference, or participate in a face-to face workshop. This blended approach to microlearning can also be a prescription to deliver larger competency-based curricula, such as supervisor core training, where there are many learning modules, each with a discrete skillset to master. For example, at the end of each online learning module, onsite workshops can be held to allow collaborative application and reinforcement of information presented in the online microlessons. Competency-based microlearning is a recipe for a truly innovative approach to e-learning. In fact, competency-based microlearning includes all the qualities outlined by Allen, Dirksen, Quinn, and Thalheimer (2014) in "The Serious E-Learning Manifesto" that are required to create a valuable learning experience. It employs spacing practice, creates challenges that have impact and meaning to learners, provides mechanisms to become emotionally engaged in authentic contexts, and encourages learners to problem solve and apply realistic solutions.

\section{Conclusion}

As organizations shift their focus from instructor-led workshops to more online classes, they need to be cognizant of innovative teaching techniques, research proven strategies, and ways to engage learners in realistic contexts to improve performance. Using microlearning, there is not much need to reserve specific learning times. Stitched into our daily lives through social media and corporate intranets on their smartphones, computers, and tablets, microlearning allows employees to be both productive and increase their knowledge at the same time. Microlearning is much more than just small chunks of justin-time learning delivered in media-rich formats to a variety of mobile devices. It can facilitate knowledge acquisition in the workplace by engaging and motivating employees to communicate and apply what they have learned. Integrated into knowledge management applications and situational mentoring, microlearning can facilitate the delivery of elusive tacit information and institutional knowledge. Institutional tacit knowledge is difficult to transfer to a learner without human interaction. A searchable, indexed microlearning database could leverage technology to bring together mentor and 
mentee for a brief encounter where the expert could impart some nugget of wisdom and enable the learner to gain tacit knowledge, starting with a click of a button.

Lastly, competency-based microlearning can be an innovative force behind improving employee proficiency and effectiveness in achieving mission critical goals. Using such techniques as subscription learning, competency-based microlearning can be a valuable asset to learning organizations focused on improving the performance of their employees. Only when organizational leaders apply novel design approaches, such as competency-based microlearning and situational micromentoring, can the e-learning mediocrity highlighted be overcome.

\section{References}

ADEC Innovations. (2016). Micro-learning: The future of corporate learning [Web log post]. Retrieved from http://km.adec-innovations.com/resources/blog/micro-learningthe-future-of-corporate-learning/

Allen, M. W., Dirksen, J., Quinn, C., \& Thalheimer, W. (2014). A serious e-learning manifesto. In E. Biech (Ed.), ASTD handbook: The definitive reference for training and development (2nd ed.) (pp. 359-378). Alexandria, Virginia: ASTD Press.

Campion, M. A., Fink, A. A., Ruggeberg, B. J., Carr, L., Phillips, G. M., \& Odman, R. B. (2011). Doing competencies well: Best practices in competency modeling. Personnel Psychology, 64(1), 225-262.

Davenport, T. H. (1994). Saving its soul: Human centered information management. Harvard Business Review, 72(2), 119-131.

Fox, A. (2016). Microlearning for effective performance management. TD Magazine, 70(4), 116-117.

Gerbier, E., \& Toppino, T. C. (2015). The effect of distributed practice: Neuroscience, cognition, and education. Trends in Neuroscience and Education 4(3), 49-59.

Giurgiu, L. (2017). Microlearning an evolving elearning trend. Scientific Bulletin, 22(1), $18-23$.

Hartley, D. (2010). Is there macro value in microlearning? Chief Learning Officer, 9(7) $30-43$.

Hughes, R. C., \& Rycus, J. S. (1989). Target: Competent staff; competency-based inservice training for child welfare. Washington, DC: Child Welfare League of America, Inc.

McCabe, S. (2016). The new CPE: Education as competitive advantage. Accounting Today, 30(3), 1, 29. Retrieved from https://www.accountingtoday.com/news/the-newcpe-education-as-competitive-advantage

Overton, L. (2011, June 27). Benchmarking can help improve learning and development initiatives. HR. Hetrieved from http://www.hrmagazine.co.uk/hro/features/1019695/benchmarking-help-improvelearning-development-initiatives

Pandey, A. (2016, April 11). 5 killer examples: How to use microlearning-based training effectively. [Web log post]. Retrieved from https://elearningindustry.com/5-killerexamples-use-microlearning-based-training-effectively

Paul, A. M. (2016). Microlearning 101. HR Magazine, 61(4), 36-42.

Poulin, M. (2013). In learning, size matters. Chief Learning Officer, 12(2), 38-56.

Rosenberg, M. (2014). Knowledge management: An introduction for T\&D professionals. In E. Biech (Ed.), ASTD handbook: The definitive reference for training and development (2nd ed., pp. 659-671). Alexandria, VA: ASTD Press.

Salopek, J. (2016). Mobile and social learning attracts, equips young insurance agents. 
TD Magazine, 70(10), 42-44.

Shatto, A. B., \& Ruiz, J. (2018, January 16). Zooming in on purpose-driven microlearning. Chief Learning Officer. Retrieved from http://www.clomedia.com/2018/01/16/zooming-purpose-driven-microlearning/

Thalheimer, W. (2014, July 08). Stuck in an e-learning box? Try subscription learning. [Web log post]. Retrieved from https://www.td.org/Publications/Blogs/L-and-DBlog/2014/07/Stuck-in-An-E-Learning-Box-Try-Subscription-Learning

Tipton, S. (2017, May/June). Maximizing microlearning. Training. Retrieved from https://trainingmag.com/trgmag-article/maximizing-microlearning

Willers, A. (2016). Compliance training: Knowledge management through microlearning. [Web log post]. Retrieved from https://www.coursepath.com/compliance-trainingknowledge-management-through-microlearning 